\title{
Detection and treatment of omega-3 fatty acid deficiency in psychiatric practice: Rationale and implementation
}

\author{
Erik Messamore ${ }^{1,2}$ and Robert K. McNamara ${ }^{1 *}$
}

\begin{abstract}
A body of translational evidence has implicated dietary deficiency in long-chain omega-3 (LCn-3) fatty acids, including eicosapenaenoic acid (EPA) and docosahexaenoic acid (DHA), in the pathophysiology and potentially etiology of different psychiatric disorders. Case-control studies have consistently observed low erythrocyte (red blood cell) EPA and/or DHA levels in patients with major depressive disorder, bipolar disorder, schizophrenia, and attention deficit hyperactivity disorder. Low erythrocyte EPA + DHA biostatus can be treated with fish oil-based formulations containing preformed EPA + DHA, and extant evidence suggests that fish oil supplementation is safe and well-tolerated and may have therapeutic benefits. These and other data provide a rationale for screening for and treating LCn-3 fatty acid deficiency in patients with psychiatric illness. To this end, we have implemented a pilot program that routinely measures blood fatty acid levels in psychiatric patients entering a residential inpatient clinic. To date over 130 blood samples, primarily from patients with treatment-refractory mood or anxiety disorders, have been collected and analyzed. Our initial results indicate that the majority (75 \%) of patients exhibit whole blood EPA + DHA levels at $\leq 4$ percent of total fatty acid composition, a rate that is significantly higher than general population norms (25\%). In a sub-set of cases, corrective treatment with fish oil-based products has resulted in improvements in psychiatric symptoms without notable side effects. In view of the urgent need for improvements in conventional treatment algorithms, these preliminary findings provide important support for expanding this approach in routine psychiatric practice.
\end{abstract}

Keywords: Long-chain omega-3 fatty acids, Eicosapentaenoic acid (EPA), Docosahexaenoic acid (DHA), Bipolar disorder, Major depressive disorder, Schizophrenia, ADHD

\section{Background}

Limited efficacy and adverse side-effects associated with conventional psychotropic medications used for the treatment of psychitaric disorders highlight an urgent need to identify modifiable risk and resilience mechanisms to inform improvements in current treatment algorithms. Over the past three decades a substantial body of evidence has implicated a dietary deficiency in long-chain omega-3 (LCn-3) fatty acids, eicosapenaenoic acid (EPA) and docosahexaenoic acid (DHA), in the pathophysiology of different recurrent psychiatric disorders, including major depressive

\footnotetext{
* Correspondence: robert.mcnamara@uc.edu

${ }^{1}$ Department of Psychiatry and Behavioral Neuroscience, University of

Cincinnati College of Medicine, 260 Stetson Street, Rm. 3306, Cincinnati, OH 45218-0516, USA

Full list of author information is available at the end of the article
}

disorder (MDD), bipolar disorder, schizophrenia, and attention deficit hyperactivity disorder (ADHD). While this body of evidence has been slow to impact conventional psychiatric training and practice, the field is slowing evolving and nutritional medicine is gaining credibility [1].

This review provides a brief overview of evidence implicating LCn-3 fatty acid deficiency in the pathophysiology and potentially etiology or recurrent psychiatric disorders, and then discusses strategies to translate this evidence into clinical screening and treatment algorithms. We present preliminary data from a recently implemented pilot program which routinely measures blood fatty acid levels in psychiatric patients entering a residential inpatient clinic. Four notable cases that illustrate the benefits resulting from detecting and treating LCn-3 fatty acid deficiency are presented. 


\section{LCn-3 fatty acids}

As background, omega-3 (n-3) and omega- $6(n-6)$ fatty acids are members of the polyunsaturated fatty acid (PUFA) family. Prominent dietary sources of the shortchain $n-3$ fatty acid precursor $\alpha$-linolenic acid (ALA, 18:3n-3) include flaxseed, linseed, canola, soy, and perilla oils. Prominent dietary sources of the short-chain $n-6$ fatty acid precursor linoleic acid (18:2n-6) include safflower, soy, and corn oils. These PUFAs are considered 'essential' because mammals are entirely dependent on dietary sources to procure and maintain adequate concentrations in peripheral and central tissues. Longchain (LC) fatty acids derived from these short-chain precursors require a series of common and competitive biosynthetic reactions. In human subjects, however, LC fatty acid biosynthesis is extremely inefficient, and dietary intake of preformed LCn-3 and LCn-6 fatty acids is significantly more effective for increasing peripheral and presumably central levels [2-6]. Preformed LCn-3 fatty acids including EPA (20:5n-3) and DHA (22:6n-3) can be obtained directly from fatty cold water fish, including salmon, trout, tuna, as well as fish oil and algal-derived supplements, and preformed LCn- 6 fatty acids including arachidonic acid (AA, 20:4n-6) can be obtained directly from animal-based foods including beef, chicken, and eggs.

\section{Animal neurodevelopmental studies}

Animal studies have provided important insight into the role of dietary LCn-3 fatty acids in the maturation of multiple neuronal systems implicated in the pathoetiology and treatment of psychiatric disorders. The advantage of animal studies is the ability to systematically and selectively manipulate dietary $n-3$ fatty acid intake and to control myriad extraneous variables that frequently confound interpretation of clinical studies. In general, rodent feeding studies have demonstrated that cortical accrual of DHA, the primary LCn-3 fatty acid in mammalian brain, during perinatal development is positively associated with cortical neurogenesis [7-9], neuroblast migration [10], neuronal differentiation [11], neurotrophic factor (NGF, BDNF) expression [12, 13], nerve growth factor-induced neurite outgrowth and synaptogenesis [14-17], and synaptic pruning [18]. Cortical DHA deficiency during development is also associated with neuroinflammation [19], and an enduring dysregulation in multiple neurotransmitter systems including dopamine and serotonin which are reversible with early, but not later, postnatal $n-3$ fatty acid supplementation $[20,21]$. In addition to neurotrophic and anti-inflammatory effects, DHA and its bioactive metabolites are protective against a variety of insults associated with oxidative stress and lipid peroxidation in the fetal and adult rat brain [22-33]. Behavioral studies suggest that development deficits in brain DHA accrual are associated with elevated behavioral indices of depression that emerge after puberty [34, 35]. In contrast, dietary fish oil fortification significantly decreases depression-like behavior similar to antidepressant medications [36, 37]. These and other data highlight the importance of DHA for normal brain maturation.

In non-human primates, dietary-induced $n-3$ fatty acid deficiency during development is associated with deficits in visual attention [38], polydipsia [39], and deficits in visual acuity and electroretinogram abnormalities [40, 41]. Electroretinogram abnormalities have also been observed in neonatal baboons born preterm [42]. Perinatal $n-3$ fatty acid deficiency is associated increased home cage stereotypy and locomotion bouts [43], which is consistent with dysregulated mesolimbic dopamine activity. A neuroimaging study found that resting-state functional connectivity among prefrontal cortical networks was impaired in monkeys raised on an $n-3$ fatty acid deficient diet compared with monkeys raised on fish oil-fortified diet [44]. Specifically, $n-3$ fatty acid deficiency during perinatal development was associated with reduced resting-state connectivity between the dorsal anterior insula (seed-region) and ventromedial, orbitofrontal, and dorsolateral prefrontal regions, as well as superior temporal and medial parietal regions, compared with monkeys raised on a fish oil-fortified diet. A positron emission tomography study demonstrated that dietary supplementation with DHA improves the decline in neurovascular coupling observed in aged monkeys [45]. As with rodents, these findings suggest that low cortical DHA status is associated with a range of enduring neurodevelopmental abnormalities.

\section{Human neurodevelopmental studies}

During pregnancy DHA accumulates in human neonatal brain tissue at an accelerated rate during the third trimester in association with rapid changes in cortical structural maturation [46, 47]. Prospective longitudinal studies have observed a positive relationship between fetal cord blood DHA levels and neurodevelopmental outcomes in older children [48-54]. As observed in non-human primates [55], human infants born preterm exhibit lower erythrocyte and postmortem cortical DHA concentrations compared with term infants [56-60]. Preterm birth and/ or low birth weight is associated with increased risk for developing ADHD in childhood [61-63], and mood, anxiety, and psychotic disorders during adolescence and young adulthood independent of maternal history of psychiatric illness [64-69]. Studies also suggest that longer breastfeeding duration, a putative surrogate for early postnatal DHA intake, is associated with better neurocognitive outcomes [70-72] and decreased risk for ADHD [73-76]. Recent neuroimaging findings suggest that low $\mathrm{LCn}-3$ fatty acid intake and biostatus may impair cortical structural and functional maturation in corticolimbic regions repeatedly implicated in psychopathology [77-86]. Together these 
findings suggest that early and uncorrected deficits in DHA accrual during development are associated with suboptimal brain development and may increase risk of psychopathology emerging in childhood and adolescence.

\section{Relevance to psychopathology Epidemiological evidence}

Cross-national epidemiological surveys have observed a significant inverse correlation between per capita fish or seafood consumption (primary dietary sources of preformed $\mathrm{EPA}+\mathrm{DHA}$ ) and lifetime prevalence rates of MDD [87, 88], postpartum depression [89], and bipolar spectrum disorders [90]. While the prevalence rates of schizophrenia appear to be consistent across different countries and not associated with per capita fish or seafood consumption [88], functional outcomes are better in counties with higher per capita intake of vegetables, fish or seafood [91]. There is also large crossnational variation in the prevalence rates of ADHD, with lower rates being observed in Asian countries compared with Western counties [92]. Cross-sectional studies similarly suggest that habitual diets low in LCn-3 fatty acids are associated with increased prevalence rates of depressive symptoms in adolescents [93-96]. A retrospective study found that the shift away from fish-based to Western diets in Arctic communities was associated with increased rates of seasonal affective disorder, depression, suicide, and cardiovascular disease [97]. While these findings provide indirect support for an inverse association between fish-based diets and prevalence rates of some psychiatric disorders, most notably depression, myriad variables may also be protective either individually or in combination with fish intake.

Several lines of evidence also suggest that increasing LCn-3 fatty acid status may reduce risk of suicide, a primary cause of excess premature mortality in mood and psychotic disorders [98-101]. First, cross-sectional epidemiological surveys have observed an inverse correlation between dietary $\mathrm{LCn}-3$ fatty acid intake and the prevalence of suicidal ideation in the general population in Finland [102], and that seasonal variations in violent suicide rates coincide with seasonal variations in serum LCn-3 fatty acid levels [103]. In two case-control studies, erythrocyte or plasma $\mathrm{LC} n-3$ fatty acid levels were significantly lower in suicidal patients [104, 105], and a prospective surveillance study found that low baseline plasma DHA composition was a significant predictor of future suicidal attempts in medication-free patients with MDD [106]. Two controlled trials found that chronic (12 week) dietary $\mathrm{LCn}-3$ fatty acid treatment reduced suicidality in MDD patients [107, 108]. However, prospective cohort studies conducted in the United States (U.S.) have not observed an association between LCn-3 fatty acid intake and completed suicide in the general population [109]. Therefore, while extant evidence suggests that increasing $\mathrm{LCn}-3$ fatty acid status in patients with psychiatric illness may be protective against suicidality, additional research is needed to evaluate whether depressed mood mediates this effect.

Excess premature mortality in patients with mood and psychotic disorders is also attributable in part to cardiovascular-related diseases [98-101], and associated risk factors are apparent early in the course of illness (i.e., in adolescents)[110]. Multiple lines of evidence suggest that LCn-3 fatty acid deficiency may increase risk for cardiovascular disease morbidity and mortality [111]. Crossnational epidemiological studies have observed reduced prevalence rates of coronary heart disease morbidity and mortality in populations whose habitual diets include fish [112]. Fatty acid composition studies have found an inverse correlation between erythrocyte EPA + DHA levels and cardiovascular risk factors including elevated serum triglyceride and pro-inflammatory molecules [113, 114]. LCn-3 fatty acid supplementation is efficacious for the treatment of elevated serum triglyceride levels, an independent risk factor for cardiovascular disease, and prescription fish oil-based products have been approved by the U.S. Food and Drug Administration (FDA) for the treatment of hypertriglyceridemia [115]. Prospective studies suggest that low baseline erythrocyte EPA + DHA ('omega-3 index') levels are associated with increased risk of sudden cardiac arrest [116-118]. It is relevant, therefore, that the low erythrocyte EPA + DHA levels observed in patients with mood and psychotic disorders are similar to those observed in patients suffering acute coronary syndrome [119], and would be anticipated to increase their risk for sudden cardiac arrest (Fig. 1). While the effects of LCn-3 fatty acid supplementation on cardiovascular events and sudden cardiac arrest in patients with a history of cardiovascular disease have been equivocal [120], primary prevention studies in subjects without a history of cardiovascular disease [121] or subjects at high-risk for cardiovascular disease [122] suggest that increasing $\mathrm{LCn}-3$ fatty acid biostatus may have protective benefits. While there have been no $\mathrm{LCn}-3$ fatty acid primary prevention studies conducted in patients with mood or psychotic disorders, existing evidence provides a rationale for identifying and treating $\mathrm{LC} n-3$ fatty acid deficiency in psychiatric patients, particularly those presenting with cardiovascular risk factors.

\section{Biological evidence}

Cross-national habitual dietary fish intake is positively correlated with erythrocyte membrane EPA + DHA composition [123, 124], and fish oil supplementation increases erythrocyte EPA + DHA composition in a linear dose-dependent manner [125]. Several independent case- 


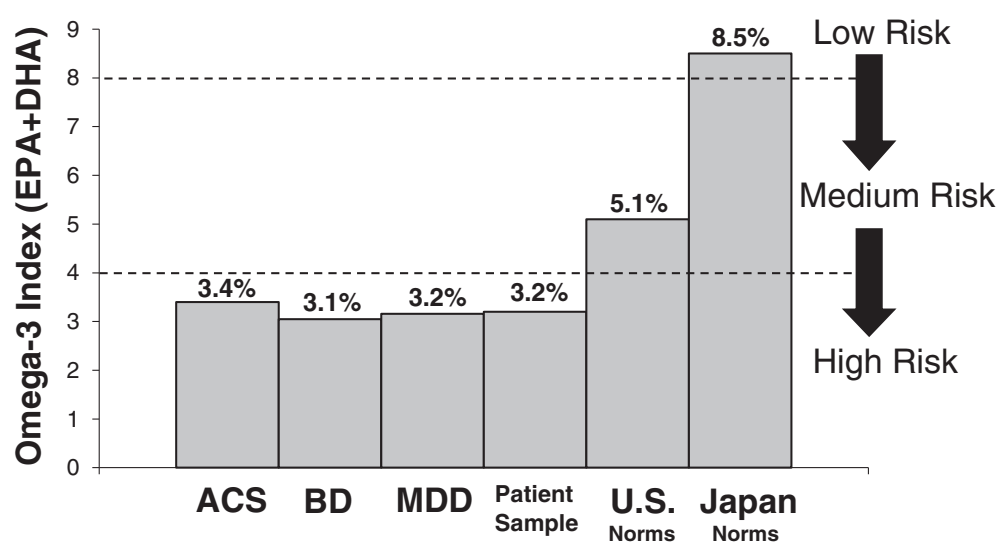

Fig. 1 Comparison of mean EPA + DHA levels in adult patients with acute coronary syndrome (ACS) residing in the U.S. (erythrocytes, $n=768)$ [119], first-episode bipolar disorder (BD) (erythrocytes, $n=40$ ) [130] and adolescent MDD (erythrocytes, $n=20$ ) [134] patients residing in the Cincinnati area, psychiatric patients admitted to the inpatient clinic at The Lindner Center of HOPE, Cincinnati (whole blood, $n=131$ ), normative values from a cohort subjects residing in the U.S. (whole blood, $n=27,414$, http://www.omegaquant.com/fatty-acids-regularly-measured/), and adults residing in Japan (erythrocytes, $n=456$ ) [124]. Proposed 'risk zones' for sudden cardiac death derived from prospective longitudinal studies are indicated [118]. Note that psychiatric patients exhibit EPA + DHA levels that are similar to patients with ACS and place them at high risk for sudden cardiac arrest. It is proposed that similar 'risk zones' be adopted in psychiatric practice to identify patients requiring corrective LCn-3 fatty acid supplementation

control studies from different countries have investigated erythrocyte and/or plasma phospholipid EPA + DHA levels in patients with psychiatric disorders. A metaanalysis of 14 case-control studies found significant deficits in EPA and DHA in plasma and erythrocytes from MDD patients [126]. In bipolar patients, four studies observed significant erythrocyte DHA and/or EPA deficits compared with healthy controls [127-130]. Crosssectional studies have similarly found that pediatric and adolescent patients with or at ultra-high risk for mood disorders exhibit erythrocyte EPA + DHA deficits compared with healthy youth [131-134]. Robust erythrocyte $\mathrm{EPA}+\mathrm{DHA}$ deficits were also observed in non-depressed patients with social anxiety disorder [135], and plasma $\mathrm{EPA}+\mathrm{DHA}$ deficits were observed in MDD patients with comorbid anxiety disorders [136]. Medication-naïve firstepisode psychotic patients exhibit erythrocyte DHA and AA deficits compared with healthy controls [137-139], and a recent meta-analysis of 18 case-control studies observed significant DHA and AA deficits in schizophrenic patients [140]. A recent meta-analysis of nine crosssectional studies observed significantly lower blood EPA + DHA levels in ADHD children compared with healthy controls [141]. Together, these studies provide strong evidence that different psychiatric disorders are characterized by low blood DHA and/or EPA biostatus which coincides with, and may precede, the initial onset of psychopathology.

Adult human erythrocyte and frontal cortex DHA levels are positively correlated [142], and a growing number of case-control studies have investigated the fatty acid composition of postmortem frontal gray matter from patients with psychiatric disorders. Some studies have observed lower LCn-3 fatty acid levels [143-147] while others have not [148-150]. Limitations associated with the postmortem approach may contribute to discrepant results [151]. Nevertheless, emerging evidence from neuroimaging studies provide support for a positive association between LCn-3 fatty acid intake or blood levels on cortical structural and functional integrity over the lifespan [77-86]. For example, greater habitual dietary $\mathrm{LC} n-3$ fatty acid intake, which is positively correlated with erythrocyte EPA + DHA composition, was associated with larger cortical gray matter volumes in several corticolimbic regions including the anterior cingulate cortex, hippocampus, and amygdala [83]. It is relevant, therefore, that patients with psychiatric disorders commonly exhibit gray matter volume deficits in the anterior cingulate cortex, hippocampus, and amygdala [152-154]. Moreover, a recent study found that fish oil supplementation increased white matter microstructural integrity in MDD patients in association with reductions in depression symptom severity [155]. Together these findings suggest that there may be a link between low LCn-3 fatty acid biostatus and deficits in corticolimbic structural and functional integrity observed in patients with psychiatric disorders.

\section{LCn-3 fatty acid supplementation}

Dietary LCn-3 fatty acid supplementation has been found to significantly increase erythrocyte $\mathrm{LCn}-3$ fatty acid levels in different patient populations [138, 156-158]. This observation indicates that $\mathrm{LCn}-3$ fatty acid deficits in psychiatric patients are modifiable by increasing dietary $\mathrm{LC} n-3$ fatty acid intake. Meta-analyses of controlled trials suggest that $\mathrm{LCn}-3$ fatty acid supplementation may be effective for reducing attention deficits in pediatric and adolescent 
ADHD patients [141, 159]. Accumulating evidence suggests that $\mathrm{LCn}-3$ fatty acid supplementation may be efficacious for the treatment of positive and negative symptoms in patients with or at ultra-high risk for developing schizophrenia [156, 160, 161], and for preventing or delaying the onset of psychosis in ultra-high risk youth [156]. A recent meta-analysis of controlled trials suggests that $\mathrm{LCn}-3$ fatty acids may be efficacious during the prodromal stage and in first-episode psychotic patients but not in patients with chronic schizophrenia [162]. These data suggest that early correction of $\mathrm{LCn}-3$ fatty acid deficits may have greater efficacy compared with treatment initiated following chronic illness.

Preliminary trials have found that LCn-3 fatty acid supplementation, either as monotherapy or adjunctive treatment, significantly reduces depression and manic symptom severity in pediatric and adolescent patients $[134,157,158$, 163]. Meta-analyses of controlled trials have observed a significant advantage of $\mathrm{LC} n-3$ fatty acid supplementation over placebo for reducing depressive symptoms in patients with MDD [164, 165] or bipolar disorder [166]. A recent metaanalysis conducted on controlled trials employing exclusively adult MDD patients observed a small-modest benefit for reducing depressive symptoms [167]. In the latter study, the authors concluded that this effect was unlikely to be clinically meaningful and that existing evidence was low quality. Indeed, heterogeneity in study design in terms of daily dose, EPA:DHA ratio, trial duration, concomitant psychotropic medications, use of a bioactive placebo (i.e., olive oil), sample size, and baseline symptom severity likely contribute substantial variability. It is also important to recognize that neurostructural and neurochemical perturbations resulting from $\mathrm{LCn}-3$ fatty acid deficiency during development may not be reversible with shortterm supplementation. This is supported by rodent studies finding that enduring impairments in serotonin and dopamine neurotransmission resulting from perinatal $n-3$ fatty acid deficiency are reversible with early but not later $n-3$ fatty acid supplementation despite normalization of $\mathrm{LCn}$ 3 fatty acid biostatus [20, 21]. Therefore, detection and treatment of LCn-3 fatty acid deficiency early in the course of illness may be required to exert the greatest protection against recurrent depressive symptoms.

In many controlled LCn-3 fatty acid intervention studies observing benefits for depressive symptoms, patients were also receiving conventional antidepressant medications. This suggests that adjunctive $\mathrm{LC} n-3$ fatty acid treatment may augment the therapeutic efficacy of antidepressant medications. This is directly supported by studies comparing selective serotonin reuptake inhibitor (SSRI) treatment with or without adjunctive $\mathrm{LCn}-3$ fatty acids in patients with MDD. In these studies, adjunctive $\mathrm{LC} n-3$ fatty acid treatment augmented the therapeutic efficacy of fluoxetine [168] or citalopram [169]. Additionally, adjunctive LCn-3 fatty acid treatment was found to reduce depression symptom severity in adolescent and adult MDD patients that were refractory to standard antidepressant treatment $[108,134]$. Adjunctive LCn-3 fatty acid treatment was also found to reduce relapse rates in predominantly medicated adult patients with bipolar disorder [170], and to reduce manic symptom severity in medicated pediatric patients with bipolar disorder [158]. In patients with first-episode psychosis, adjunctive LCn-3 fatty acid (EPA) treatment accelerated treatment response, improved tolerability, and permited a 20 percent reduction in second-generation antipsychotic medication dose [171]. In addition to augmenting efficacy, adjunctive $\mathrm{LC} n-3$ fatty acid treatment may also be protective against adverse cardiometabolic [172-174] and hepatic [175-177] side-effects associated with second generation antipsychotic medications. These preliminary findings suggest that adjunctive LCn-3 fatty acid treatment may augment therapeutic efficacy and mitigate cardiometabolic side-effects associated with conventional psychotropic medications.

\section{Implementation}

In the previous sections we briefly summarized a body of translational evidence which suggests that $\mathrm{LCn}-3$ fatty acid deficiency, particularly during perinatal development, may represent a modifiable risk factor for psychopathology. Among these findings, meta-analyses of independent case-control studies demonstrate that patients with different psychiatric disorders, including mood, psychotic, and attentional disorders, exhibit significantly lower blood levels of EPA and/or DHA compared with healthy demographically similar controls. Additionally, meta-analyses of several independent controlled intervention studies suggest that increasing EPA + DHA biostatus via dietary supplementation with fish oil-based products may be effective for reducing psychiatric symptoms, suicidality, and cardiometabolic risk factors. Together these and other data support routine screening for and treatment of $\mathrm{LCn}$ 3 fatty acid deficiency in patients with psychiatric disorders. Below we briefly discuss existing screening and treatment resources and general guidelines required for implementation in psychiatric practice.

\section{Diagnosing LCn-3 fatty acid deficiency}

There are currently several Clinical Laboratory Improvement Amendments (CLIA)-certified laboratory facilities that routinely perform blood fatty acid analyses by gas-liquid chromatography (GLC). While the American Medical Association has several current procedural terminology (CPT) codes for blood fatty acid analysis by GLC $(82725,82544,82492)$ and GLC testing in general (82541, 82542), reimbursement for these tests is ultimately at the discretion of the insurance provider. For this procedure, whole blood $(\sim 25 \mathrm{uL})$ is obtained from a finger 
prick and is spotted and dried onto anti-oxidant treated card which is then shipped at ambient temperature. The GLC analysis involves the determination of different fatty acids including EPA + DHA which are reported as a percentage of total fatty acids. Fatty acid levels are returned to the physician in approximately 2 weeks. Individual fatty acid levels can be compared to U.S. population norms. Against this reference, a patient's fatty acid levels can be expressed in a percentile ranking. Based on evidence that erythrocyte EPA + DHA composition of $\leq 4 \%$ of total fatty acid composition increases risk for sudden cardiac death [118], and evidence that the majority of patients with psychiatric disorders exhibit erythrocyte EPA + DHA composition of $\leq 4 \%[128,130,132,134,178]$, erythrocyte or whole blood EPA + DHA composition of $\leq 4 \%$ may be considered to be a 'state of deficiency' that requires corrective intervention. Analogous to routine cholesterol testing, this screening approach can provide a valid, reliable, and relatively non-invasive measure of a patient's EPA + DHA biostatus.

\section{Treating LCn-3 fatty acid deficiency}

Prescription ethyl ester EPA + DHA (Lovaza in the US, Omacor ${ }^{\circ}$ in Europe, GlaxoSmithKline), purified ethyl ester EPA containing no DHA (Vascepa ${ }^{\circ}$, Amarin Corporation), and a free versus ethyl ester EPA + DHA formulation (Epanova ${ }^{\circ}$, AstraZeneca) have been approved by the U.S. FDA for the treatment of hypertriglyceridemia $(\geq 500 \mathrm{mg} / \mathrm{dL})$. More recently a generic version of Lovaza has become available (Teva Pharmaceuticals USA, Inc.). Over-the-counter fish oil supplements containing similar ethyl ester EPA + DHA concentrations are also widely available. It is important to note, however, that no $\mathrm{LCn}-3$ fatty acid formulation is currently approved by the FDA for the treatment of any psychiatric disorder.

The American Psychiatric Association has adopted the consensus recommendations of the American Heart Association for an EPA + DHA dose of $1 \mathrm{~g} / \mathrm{d}$ in patients with MDD [179]. The American Heart Association also recommends $3 \mathrm{~g} / \mathrm{d} \mathrm{EPA}+\mathrm{DHA}$ for reducing elevated triglyceride levels. Controlled intervention studies have in general found that daily doses in the range of $0.2-2 \mathrm{~g} /$ $\mathrm{d}$ of EPA + DHA may be efficacious for the treatment of mood symptoms $[164,165]$. Emerging evidence also suggests that a larger ratio of EPA to DHA may be more efficacious for treating depressive symptoms [165] as well as ADHD symptoms [159]. A dose-response study found that EPA + DHA supplementation at doses between $300-900 \mathrm{mg} / \mathrm{d}$ are sufficient to increase erythrocyte EPA + DHA composition in non-psychiatric subjects to levels thought to be cardioprotective [125]. As with other medications, upward dose titration may be required as clinically indicated. For example, in an open-label flexible dosing study 8-week $\mathrm{LCn}$-3 fatty acid monotherapy led to a statistically significant reduction in manic symptom severity scores in pediatric bipolar patients [157]. In this study the starting dose was $1.3 \mathrm{~g} / \mathrm{d}$ of EPA + DHA, the maximum dose was $4.3 \mathrm{~g} / \mathrm{d}$, and the mean dose was $2.6 \mathrm{~g} / \mathrm{d}$. While there is a need for additional dose-titrating secondary prevention trials to elucidate optimal LCn-3 fatty acid dosing strategies to maximize therapeutic effects, existing evidence suggests that EPA + DHA doses in the range of 1-4 g/d are sufficient to treat erythrocyte EPA + DHA deficits in patients with psychiatric illness.

The U.S. Food and Drug Administration (FDA) considers $\mathrm{LC} n-3$ fatty acid doses up to $3 \mathrm{~g} / \mathrm{d}$ to be 'generally regarded as safe'. Potential adverse events associated with LCn-3 fatty acid treatment include gastrointestinal disturbances, including nausea, diarrhea, gastroesophageal reflux, eructation, and less commonly emesis. In double-blind clinical trials in adolescent and adult patients, the principal adverse events reported after chronic (8-12 weeks) treatment with LCn-3 fatty acid supplements were gastrointestinal problems, and were considered mild and not clinically significant [134, 158, 163, 179]. To minimize the gastrointestinal adverse events associated with $\mathrm{LCn}-3$ fatty acids, patients should be instructed to take their pills with meals. Although taking fish oil at high doses $(>3 \mathrm{~g} / \mathrm{d})$ has been associated in isolated cases with increased bleeding time in subjects also taking anticoagulant medications [180], controlled clinical trials have found that chronic high dose EPA + DHA alone or in combination with aspirin does not increase risk for clinically-significant increases in bleeding time [181-183]. Another safety consideration involves the potential threat of contamination of fish and seafood with methyl mercury and other environmental pollutants. However, most fish oil supplements are highly purified and do not exceed U.S. FDA limits for methyl mercury and other environmental contaminants. As with all medications, patients should be informed of potential risks associated with fish oil-based products, and patients with an allergy to shellfish or seafood should be closely monitored.

\section{Proof-of-concept}

The Lindner Center of HOPE (http://www.lindnercenterofhope.org) is a university-affiliated mental health care center located in Mason, a suburb of Cincinnati, Ohio. The center houses an outpatient mental health clinic, acute care hospital services, and specialized residential diagnostic assessment programs. The residential diagnostic assessment programs serve approximately 280 pediatric, adolescent, and adult patients annually. Patients are typically referred to these programs by mental health clinicians when there is diagnostic uncertainty, and multiple treatment failures is the most frequent cause of 
diagnostic uncertainty. Complex affective or anxiety disorders are the most common reasons for referral. Diagnostic assessment within these programs includes medical examination, neurological examination, laboratory studies, brain imaging or EEG when indicated, neuropsychological testing, objective personality assessment, structured diagnostic interview, serial mental status evaluations, continuous behavioral observations in the residential milieu, and acquisition of collateral behavioral histories from families, close associates, or outpatient healthcare providers.

Beginning in mid-2014, measurement of whole blood fatty acid levels was implimented as part of the routine laboratory assessment. Dried blood spots are sent to OmegaQuant, LLC for analysis. To date over 131 patient blood samples have been collected and analyzed. The majority of these patients were referred for mood or anxiety disorders and had previously responded poorly to standard outpatient care (i.e., treatment-refractory). Our initial results suggest that the majority $(75 \%)$ of patients exhibit whole blood EPA + DHA levels at $\leq 4$ percent of total fatty acid composition. This rate is significantly greater than general U.S. population norms (25\%) based on 27,414 subjects residing in the U.S. $(\mathrm{p} \leq 0.0001)$ (Fig. 2a). The overall $(n=131)$ EPA + DHA mean for patients is $3.2 \%$ of total fatty acid composition, which is at the 8th percentile of fatty acid norms and lower than the mean observed for the general U.S. population (5.1\%, 25th percentile) (Fig. 2b). It is notable that the mean EPA + DHA level observed in psychiatric patients is similar to that observed in erythrocytes from U.S. adult patients suffering acute coronary syndrome (3.4 \%)[119] (Fig. 1), which places them at elevated risk for developing sudden cardiac arrest [118]. Our initial results therefore support prior evidence that psychiatric patients exhibit very low EPA + DHA levels. Below we describe four notable cases that illustrate the benefits resulting from detecting and treating $\mathrm{LCn}-3$ fatty acid deficiency.

\section{Clinical vignettes}

\section{Case 1}

A 24 year old man with childhood onset of psychiatric symptoms, at least 4 prior psychiatric hospitalizations, and historical diagnoses of type 2 bipolar disorder, attention deficit-hyperactivity disorder, eating disorder, and borderline personality disorder was found to have an omega-3 index (EPA + DHA) of $2.98 \%$ which placed him at the 4th percentile of U.S. population norms. Based on this, he was prescribed Lovaza (ethyl-EPA/ ethyl-DHA) at a daily dose of $1,860 \mathrm{mg}$ EPA and 1,500 mg DHA (total EPA + DHA dose: $3,360 \mathrm{mg} / \mathrm{d}$ ) which was covered by his insurer. Based on his history of bipolar disorder, his divalproex prescription was continued. However, based on lack of efficacy his vilazadone and lisdexamphetamine were discontinued. Within three weeks the patient reported to his outpatient psychiatrist that his mental status, mood and mood stability, and overall level of social and occupational functioning were the best he could ever recall. At 6-month follow-up his omega-3 index (EPA + DHA) had risen to $7.69 \%$ (85th percentile), and he reported that he was enjoying a continued stability previously unknown to him. He credited his success to the addition of the ethyl-EPA/ethyl-DHA, stating that he had never had such benefit associated with divalproex. He also discounted the possibility that
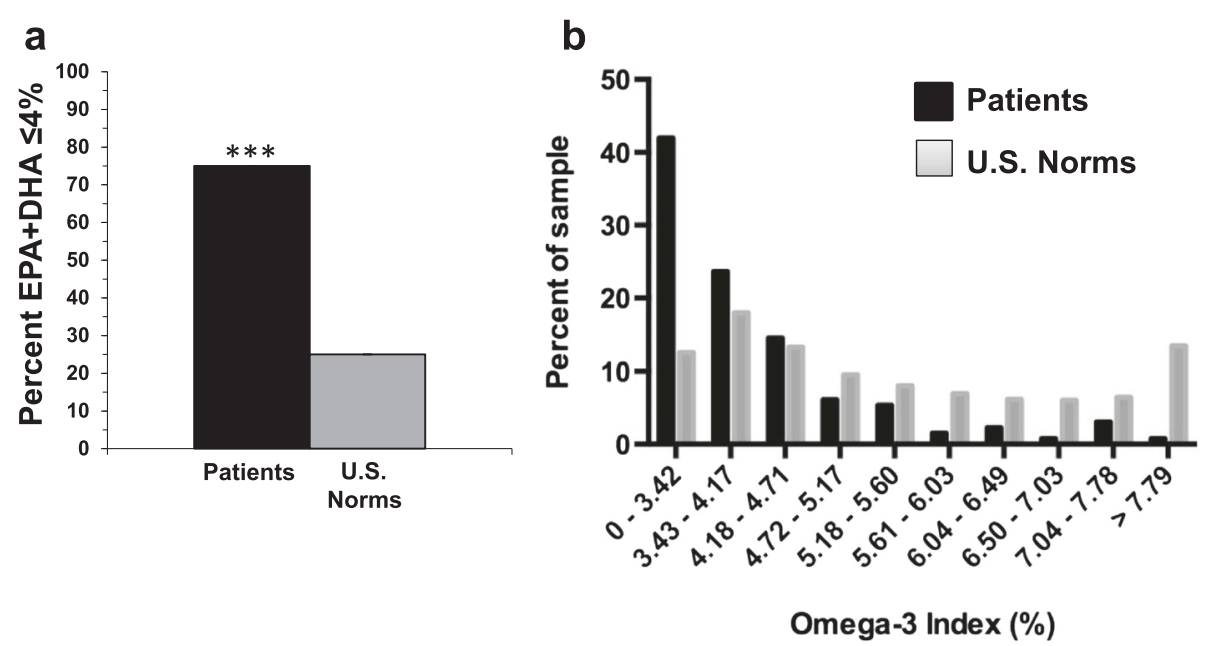

Fig. 2 a The percentage of subjects residing in the U.S. $(n=27,426)$ and psychiatric patients admitted to the inpatient clinic at The Lindner Center of HOPE $(n=131)$ with an 'omega-3 index' (whole blood EPA + DHA) of $\leq 4.0 \%$ of total fatty acid composition. b Histogram comparing 'omega-3 index' (EPA + DHA) frequency distribution of the psychiatric patient sample to the OmegaQuant reference sample. Note that the majority $(75 \%)$ of psychiatric patients exhibit whole blood EPA + DHA levels at $\leq 4$ percent of total fatty acid composition, a rate that is significantly greater than general U.S. population norms ( $25 \%$, ***P $\leq 0.0001$, Chi-Square) 
discontinuation of his antidepressant and stimulant medications were relevant, since there had been many prior episodes of being off these medications with no recalled equal benefit.

\section{Case 2}

A 27 year old woman was admitted with a chief complaint of emotional dysregulation. Although there was a family history of bipolar disorder, the patient had no history of manic episodes; however, she did engage in frequent suicidal gestures and self-injurious behaviors. The patient also had experienced simple partial seizures since early childhood. Her omega-3 index (EPA + DHA) was $2.93 \%$ of total fatty acids (3rd percentile). Based on the family history of bipolar disorder, lithium was added to her existing medications. Her topiramate and oxcarbazapine were continued. Based on the low level of omega-3 fatty acids, she was also started on Lovaza (ethyl-EPA/ethyl-DHA) at a dose of 1860/1500 mg daily (total EPA + DHA: 3,360 mg/d). Consistent with recent evidence that fish oil supplementation elevates seizure thresholds and reduces seizure frequency in epileptic patients $[184,185]$, at six-month follow-up she had been seizure-free, was able to live independently and reported no self-injurious behaviors.

\section{Case 3}

A 23 year old man was referred for treatment because he was contemplating suicide because he could no longer tolerate near-constant depression and anxiety. He had suffered from severe anxiety since age 5 . He had been treated with a wide variety of antidepressant medications, mood stabilizers, and stimulants since his early teens. Medications had been either ineffective or poorly tolerated. He was diagnostically enigmatic and over the course of his life had been diagnosed with anxiety disorder, major depression, bipolar disorder, and attention deficit hyperactivity disorder. Comprehensive diagnostic assessment suggested generalized anxiety disorder and bipolar disorder not otherwise specified as the most appropriate diagnoses. Fatty acids analysis revealed an omega-3 index of $3.38 \%$ (11th percentile). Because of this, addition of omega-3 fatty acids to his medications was recommended. He took an over-the-counter fish oil supplement at a dose that delivered $1600 \mathrm{mg}$ of EPA and $800 \mathrm{mg}$ of DHA per day (total EPA + DHA: 2,400 mg/d). Other treatment recommendations included: discontinuation of serotonin reuptake inhibitors, addition of lithium, and addition of a low dose of topiramate (50 mg nightly). He was continued on his existing $200 \mathrm{mg}$ nightly dose of quetiapine. At nine-month follow-up, he reported markedly improved social and occupational functioning and normalization of his mood. The durability of his improvements allowed for elimination of lithium and topiramate and halving of his quetiapine dose. He continued to take the EPA+DHA supplement.

\section{Case 4}

A 38 year old woman reported constitutively high anxiety levels since childhood and also described highly reactive mood and difficulty managing anger, and identified anxiety as her most pressing concern. She had tried numerous serotonin reuptake inhibitor medications with no discernable benefit. She reported a history of problematic use of alcohol and benzodiazepines, though she had not used either substance for several months prior to her assessment. She was diagnosed with anxiety disorder, not otherwise specified; benzodiazepine abuse in early full remission; and alcohol abuse in early full remission. Borderline personality traits were prominent, but criteria for a personality disorder diagnosis were not fully met. Fatty acid analysis revealed an omega-3 index of $3.25 \%$ (8th percentile). Because serotonergic medications had been historically unhelpful, she was prescribed topiramate to address mood reactivity and anxiety, and to promote sustained abstinence from alcohol, and fish oil supplementation was recommended. She elected to take an over-thecounter fish oil supplement at a dose that delivered an EPA dose of $1080 \mathrm{mg} / \mathrm{d}$ and DHA dose of $720 \mathrm{mg} / \mathrm{d}$ (total $\mathrm{EPA}+\mathrm{DHA}$ : 1,800 mg/d). At three month follow-up, she reported adherence to recommended dialectical behavior therapy and had continued to take topiramate $(50 \mathrm{mg}$ twice daily) and the fish oil supplement. She reported significant and sustained reduction of anxiety, improved mood stability, abstinence from alcohol or benzodiazepines, and improved social and interpersonal functioning.

\section{Conclusions}

There is now a substantial body of translational evidence that suggests that $\mathrm{LC} n-3$ fatty acid deficiency, particularly during active periods of brain development, is associated with neuropathogenic features that have separately been implicated in the pathophysiology of different psychiatric disorders. Moreover, major recurrent psychiatric disorders are associated with blood LCn-3 fatty acid deficiency which may increase risk for cardiovascular disease, a principle cause of excess premature mortality in patients with mood and psychotic disorders. Extant evidence suggests that $\mathrm{LCn}-3$ fatty acid supplementation is sufficient to increase LCn-3 fatty acid blood levels in psychiatric patients which may additionally have therapeutic benefits and mitigate adverse cardiometabolic risk factors. These and other data provide a strong rationale supporting routine screening for and treatment of $\mathrm{LCn}-3$ fatty acid deficiency in patients with psychiatric illness. As proof-ofconcept, we have demonstrated the feasibility of implementing blood LCn-3 fatty acid screening as well as treatment using fish oil-based formulations in a residential 
diagnostic assessment center. Consistent with prior crosssectional evidence, our preliminary results demonstrate that the majority of these patients exhibit very low blood EPA + DHA levels, and that treatment with fish oil can result in improvements in psychiatric symptoms without any notable side effects. Within the context of extant evidence and the urgent need for improvements in conventional treatment algorithms, these preliminary findings provide important support for expanding this approach in routine psychiatric clinical practice.

\section{Competing interests}

R.K.M. has received research support from Martek Biosciences Inc Inflammation Research Foundation (IRF), Ortho-McNeil Janssen, AstraZeneca, Eli Lilly, and was a member of the IRF scientific advisory board. E.M. is a psychiatric at The Lindner Center of HOPE.

\section{Authors' contributions}

E.M. is a psychiatrist at The Lindner Center of HOPE and performed the blood fatty acid analyses and associated data compilation and analyses. R.K.M. drafted the manuscript which was reviewed and edited by E.M.

\section{Acknowledgements}

This work was supported in part by National Institutes of Health grants MH097818 and DK097599 to R.K.M. Funding for the reported blood fatty acid analyses was provided by internal sources at The Lindner Center of HOPE.

\section{Author details}

${ }^{1}$ Department of Psychiatry and Behavioral Neuroscience, University of Cincinnati College of Medicine, 260 Stetson Street, Rm. 3306, Cincinnati, OH 45218-0516, USA. ${ }^{2}$ Lindner Center of HOPE, Mason, OH, USA.

Received: 8 January 2016 Accepted: 4 February 2016

Published online: 10 February 2016

\section{References}

1. Sarris J, Logan AC, Akbaraly TN, Amminger GP, Balanzá-Martínez V, Freeman $M P$, et al. International society for nutritional psychiatry research. Nutritional medicine as mainstream in psychiatry. Lancet Psychiatry. 2015;2:271-4.

2. Brenna JT, Salem N, Sinclair AJ, Cunnane SC. International Society for the Study of Fatty Acids and Lipids, ISSFAL. alpha-Linolenic acid supplementation and conversion to n-3 long-chain polyunsaturated fatty acids in humans. Prostaglandins Leukot Essent Fatty Acids. 2009;80:85-91.

3. Barceló-Coblijn G, Murphy EJ, Othman R, Moghadasian MH, Kashour T, Friel JK. Flaxseed oil and fish-oil capsule consumption alters human red blood cell n-3 fatty acid composition: a multiple-dosing trial comparing 2 sources of n-3 fatty acid. Am J Clin Nutr. 2008;88:801-9.

4. Francois CA, Connor SL, Bolewicz LC, Connor WE. Supplementing lactating women with flaxseed oil does not increase docosahexaenoic acid in their milk. Am J Clin Nutr. 2003;77:226-33.

5. Su HM, Bernardo L, Mirmiran M, Ma XH, Corso TN, Nathanielsz PW, et al. Bioequivalence of dietary alpha-linolenic and docosahexaenoic acids as sources of docosahexaenoate accretion in brain and associated organs of neonatal baboons. Pediatr Res. 1999;45:87-93.

6. Adam O, Tesche A, Wolfram G. Impact of linoleic acid intake on arachidonic acid formation and eicosanoid biosynthesis in humans. Prostaglandins Leukot Essent Fatty Acids. 2008;79:177-81.

7. Beltz BS, Tlusty MF, Benton JL, Sandeman DC. Omega-3 fatty acids upregulate adult neurogenesis. Neurosci Lett. 2007:415:154-8.

8. Coti Bertrand P, O'Kusky JR, Innis SM. Maternal dietary (n-3) fatty acid deficiency alters neurogenesis in the embryonic rat brain. J Nutr. 2006;136:1570-5.

9. Kawakita E, Hashimoto M, Shido O. Docosahexaenoic acid promotes neurogenesis in vitro and in vivo. Neuroscience. 2006;139:991-7.

10. Yavin E, Himovichi E, Eilam R. Delayed cell migration in the developing rat brain following maternal omega 3 alpha linolenic acid dietary deficiency. Neuroscience. 2009;162:1011-122.
11. Calderon F, Kim HY. Docosahexaenoic acid promotes neurite growth in hippocampal neurons. J Neurochem. 2004;90:979-88.

12. Ikemoto A, Nitta A, Furukawa S, Ohishi M, Nakamura A, Fujii Y, et al. Dietary n-3 fatty acid deficiency decreases nerve growth factor content in rat hippocampus. Neurosci Lett. 2000;285:99-102.

13. Rao JS, Ertley RN, Lee HJ, DeMar JC, Arnold JT, Rapoport SI, et al. n-3 polyunsaturated fatty acid deprivation in rats decreases frontal cortex BDNF via a p38 MAPK-dependent mechanism. Mol Psychiatry. 2007;12:36-46.

14. Cao D, Kevala K, Kim J, Moon HS, Jun SB, Lovinger D, et al. Docosahexaenoic acid promotes hippocampal neuronal development and synaptic function. J Neurochem. 2009;111:510-21.

15. Ikemoto A, Kobayashi T, Watanabe S, Okuyama H. Membrane fatty acid modifications of $\mathrm{PC} 12$ cells by arachidonate or docosahexaenoate affect neurite outgrowth but not norepinephrine release. Neurochem Res. 1997; 22:671-8.

16. Innis SM, de La Presa Owens S. Dietary fatty acid composition in pregnancy alters neurite membrane fatty acids and dopamine in newborn rat brain. J Nutr. 2001;131:118-22.

17. Martin RE, Bazan NG. Changing fatty acid content of growth cone lipids prior to synaptogenesis. J Neurochem. 1992;59:318-25.

18. de Velasco PC, Mendonça HR, Borba JM, Andrade da Costa BL, Guedes RC, Navarro DM, et al. Nutritional restriction of omega-3 fatty acids alters topographical fine tuning and leads to a delay in the critical period in the rodent visual system. Exp Neurol. 2012;234:220-9.

19. Madore C, Nadjar A, Delpech JC, Sere A, Aubert A, Portal C, et al. Nutritional n3 PUFAs deficiency during perinatal periods alters brain innate immune system and neuronal plasticity-associated genes. Brain Behav Immun. 2014;41:22-31.

20. Kodas E, Vancassel S, Lejeune B, Guilloteau D, Chalon S. Reversibility of n-3 fatty acid deficiency-induced changes in dopaminergic neurotransmission in rats: critical role of developmental stage. J Lipid Res. 2002;43:1209-19.

21. Kodas E, Galineau L, Bodard S, Vancassel S, Guilloteau D, Besnard JC, et al. Serotoninergic neurotransmission is affected by $n-3$ polyunsaturated fatty acids in the rat. J Neurochem. 2004;89:695-702.

22. Green $P$, Glozman $S$, Weiner $L$, Yavin E. Enhanced free radical scavenging and decreased lipid peroxidation in the rat fetal brain after treatment with ethyl docosahexaenoate. Biochim Biophys Acta. 2001;1532:203-12.

23. Yavin E, Brand A, Green P. Docosahexaenoic acid abundance in the brain: a biodevice to combat oxidative stress. Nutr Neurosci. 2002:5:149-57.

24. Belayev L, Khoutorova L, Atkins KD, Bazan NG. Robust docosahexaenoic acid-mediated neuroprotection in a rat model of transient, focal cerebral ischemia. Stroke. 2009:40:3121-6.

25. Blondeau N, Widmann C, Lazdunski M, Heurteaux C. Polyunsaturated fatty acids induce ischemic and epileptic tolerance. Neuroscience. 2002;109:231-41.

26. Ozyurt B, Sarsilmaz M, Akpolat N, Ozyurt H, Akyol O, Herken H, et al. The protective effects of omega-3 fatty acids against MK-801-induced neurotoxicity in prefrontal cortex of rat. Neurochem Int. 2007;50:196-202.

27. Högyes E, Nyakas C, Kiliaan A, Farkas T, Penke B, Luiten PG. Neuroprotective effect of developmental docosahexaenoic acid supplement against excitotoxic brain damage in infant rats. Neuroscience. 2003:119:999-1012.

28. Wu A, Ying Z, Gomez-Pinilla F. Dietary omega-3 fatty acids normalize BDNF levels, reduce oxidative damage, and counteract learning disability after traumatic brain injury in rats. J Neurotrauma. 2004;21:1457-67.

29. Orr SK, Palumbo S, Bosetti F, Mount HT, Kang JX, Greenwood CE, et al. Unesterified docosahexaenoic acid is protective in neuroinflammation. J Neurochem. 2013:127:378-93.

30. Tuzun F, Kumral A, Dilek M, Ozbal S, Ergur B, Yesilirmak DC, et al. Maternal omega-3 fatty acid supplementation protects against lipopolysaccharideinduced white matter injury in the neonatal rat brain. J Matern Fetal Neonatal Med. 2012;25:849-54.

31. Bailes JE, Mills JD. Docosahexaenoic acid reduces traumatic axonal injury in a rodent head injury model. J Neurotrauma. 2010;27:1617-24.

32. Kong W, Yen JH, Ganea D. Docosahexaenoic acid prevents dendritic cell maturation, inhibits antigen-specific Th1/Th17 differentiation and suppresses experimental autoimmune encephalomyelitis. Brain Behav Immun. 2011;25: 872-82.

33. Calon F, Col G. Neuroprotective action of omega-3 polyunsaturated fatty acids against neurodegenerative diseases: evidence from animal studies. Prostaglandins Leukot Essent Fatty Acids. 2007;77:287-93.

34. DeMar Jr JC, Ma K, Bell JM, Igarashi M, Greenstein D, Rapoport SI. One generation of $\mathrm{n}-3$ polyunsaturated fatty acid deprivation increases depression and aggression test scores in rats. J Lipid Res. 2006;47:172-80. 
35. Weiser MJ, Wynalda K, Salem Jr N, Butt CM. Dietary DHA during development affects depression-like behaviors and biomarkers that emerge after puberty in adolescent rats. J Lipid Res. 2015;56:151-66.

36. Huang SY, Yang HT, Chiu CC, Pariante CM, Su KP. Omega-3 fatty acids on the forced-swimming test. J Psychiatr Res. 2008:42:58-63.

37. Carlezon Jr WA, Mague SD, Parow AM, Stoll AL, Cohen BM, Renshaw PF. Antidepressant-like effects of uridine and omega-3 fatty acids are potentiated by combined treatment in rats. Biol Psychiatry. 2005;57:343-50.

38. Reisbick S, Neuringer M, Gohl E, Wald R, Anderson GJ. Visual attention in infant monkeys: effects of dietary fatty acids and age. Dev Psychol. 1997;33:387-95

39. Reisbick $S$, Neuringer M, Hasnain R, Connor WE. Polydipsia in rhesus monkeys deficient in omega-3 fatty acids. Physiol Behav. 1990;47:315-23.

40. Anderson GJ, Neuringer M, Lin DS, Connor WE. Can prenatal N-3 fatty acid deficiency be completely reversed after birth? Effects on retinal and brain biochemistry and visual function in rhesus monkeys. Pediatr Res. 2005;58:865-72.

41. Neuringer M, Connor WE, Lin DS, Barstad L, Luck S. Biochemical and functional effects of prenatal and postnatal omega 3 fatty acid deficiency on retina and brain in rhesus monkeys. Proc Natl Acad Sci U S A. 1986;83:4021-5.

42. Diau GY, Loew ER, Wijendran V, Sarkadi-Nagy E, Nathanielsz PW, Brenna JT. Docosahexaenoic and arachidonic acid influence on preterm baboon retinal composition and function. Invest Ophthalmol Vis Sci. 2003;44:4559-66.

43. Reisbick S, Neuringer M, Hasnain R, Connor WE. Home cage behavior of rhesus monkeys with long-term deficiency of omega-3 fatty acids. Physiol Behav. 1994:55:231-9.

44. Grayson DS, Kroenke CD, Neuringer M, Fair DA. Dietary omega-3 fatty acids modulate large-scale systems organization in the rhesus macaque brain. J Neurosci. 2014:34:2065-74.

45. Tsukada H, Kakiuchi T, Fukumoto D, Nishiyama S, Koga K. Docosahexaenoic acid (DHA) improves the age-related impairment of the coupling mechanism between neuronal activation and functional cerebral blood flow response: a PET study in conscious monkeys. Brain Res. 2000;862:180-6.

46. Clandinin MT, Chappell JE, Leong S, Heim T, Swyer PR, Chance GW. Intrauterine fatty acid accretion rates in human brain: implications for fatty acid requirements. Early Hum Dev. 1980;4:121-9.

47. Dubois J, Dehaene-Lambertz G, Kulikova S, Poupon C, Hüppi PS, HertzPannier $L$. The early development of brain white matter: A review of imaging studies in fetuses, newborns and infants. Neuroscience. 2014;276: 48-71.

48. Bakker EC, Ghys AJ, Kester AD, Vles JS, Dubas JS, Blanco CE, et al. Long-chain polyunsaturated fatty acids at birth and cognitive function at $7 \mathrm{y}$ of age. Eur J Clin Nutr. 2003:57:89-95.

49. Bakker EC, Hornstra G, Blanco CE, Vles JS. Relationship between long-chain polyunsaturated fatty acids at birth and motor function at 7 years of age. Eur J Clin Nutr. 2009;63:499-504.

50. Escolano-Margarit MV, Ramos R, Beyer J, Csábi G, Parrilla-Roure M, Cruz F, et al. Prenatal DHA status and neurological outcome in children at age 5. 5 years are positively associated. J Nutr. 2011;141:1216-23.

51. Jacques C, Levy E, Muckle G, Jacobson SW, Bastien C, Dewailly E, et al. Long-term effects of prenatal omega-3 fatty acid intake on visual function in school-age children. J Pediatr. 2011;158:83-90.

52. Boucher O, Burden MJ, Muckle G, Saint-Amour D, Ayotte P, Dewailly E, et al. Neurophysiologic and neurobehavioral evidence of beneficial effects of prenatal omega-3 fatty acid intake on memory function at school age. Am J Clin Nutr. 2011;93:1025-37.

53. Kohlboeck G, Glaser C, Tiesler C, Demmelmair H, Standl M, Romanos M, et al. Effect of fatty acid status in cord blood serum on children's behavioral difficulties at 10 y of age: results from the LISAplus Study. Am J Clin Nutr. 2011;94:1592-9.

54. Krabbendam L, Bakker E, Hornstra G, van Os J. Relationship between DHA status at birth and child problem behaviour at 7 years of age. Prostaglandins Leukot Essent Fatty Acids. 2007;76:29-34.

55. Sarkadi-Nagy E, Wijendran V, Diau GY, Chao AC, Hsieh AT, Turpeinen A, et al. The influence of prematurity and long chain polyunsaturate supplementation in 4-week adjusted age baboon neonate brain and related tissues. Pediatr Res. 2003;54:244-52.

56. Clandinin MT, Chappell JE, Leong S, Heim T, Swyer PR, Chance GW. Extrauterine fatty acid accretion in infant brain: implications for fatty acid requirements. Early Hum Dev. 1980;4:131-8.
57. Martinez M. Tissue levels of polyunsaturated fatty acids during early human development. J Pediatr. 1992;120:S129-138.

58. Farquharson J, Cockburn F, Patrick WA, Jamieson EC, Logan RW. Infant cerebral cortex phospholipid fatty-acid composition and diet. Lancet. 1992;340:810-3.

59. Farquharson J, Jamieson EC, Abbasi KA, Patrick WJ, Logan RW, Cockburn F. Effect of diet on the fatty acid composition of the major phospholipids of infant cerebral cortex. Arch Dis Child. 1995;72:198-203.

60. Martínez M, Mougan I. Fatty acid composition of human brain phospholipids during normal development. J Neurochem. 1998;71:2528-33.

61. Bhutta AT, Cleves MA, Casey PH, Cradock MM, Anand KJ. Cognitive and behavioral outcomes of school-aged children who were born preterm: a meta-analysis. JAMA. 2002;288:728-37.

62. Botting N, Powls A, Cooke RW, Marlow N. Attention deficit hyperactivity disorders and other psychiatric outcomes in very low birthweight children at 12 years. J Child Psychol Psychiatry. 1997;38:931-41.

63. Johnson S, Hollis C, Kochhar P, Hennessy E, Wolke D, Marlow N. Psychiatric disorders in extremely preterm children: longitudinal finding at age 11 years in the EPICure study. J Am Acad Child Adolesc Psychiatry. 2010;49:453-63.

64. Indredavik MS, Vik T, Heyerdahl S, Kulseng S, Fayers P, Brubakk AM. Psychiatric symptoms and disorders in adolescents with low birth weight. Arch Dis Child Fetal Neonatal Ed. 2004;89:445-50.

65. Indredavik MS, Vik T, Evensen KA, Skranes J, Taraldsen G, Brubakk AM. Perinatal risk and psychiatric outcome in adolescents born preterm with very low birth weight or term small for gestational age. J Dev Behav Pediatr. 2010;31:286-94.

66. Costello EJ, Worthman C, Erkanli A, Angold A. Prediction from low birth weight to female adolescent depression: a test of competing hypotheses. Arch Gen Psychiatry. 2007;64:338-44.

67. Lindström K, Lindblad F, Hjern A. Psychiatric morbidity in adolescents and young adults born preterm: a Swedish national cohort study. Pediatrics. 2009;123:47-53.

68. Nosarti C, Reichenberg A, Murray RM, Cnattingius S, Lambe MP, Yin L, et al. Preterm birth and psychiatric disorders in young adult life. Arch Gen Psychiatry. 2012;69:1-8.

69. Patton GC, Coffey C, Carlin JB, Olsson CA, Morley R. Prematurity at birth and adolescent depressive disorder. Br J Psychiatry. 2004;184:446-7.

70. Horwood LJ, Darlow BA, Mogridge N. Breast milk feeding and cognitive ability at 7-8 years. Arch Dis Child Fetal Neonatal Ed. 2001;84:F23-27.

71. Mortensen EL, Michaelsen KF, Sanders SA, Reinisch JM. The association between duration of breastfeeding and adult intelligence. JAMA. 2002;287:2365-71.

72. Oddy WH, Kendall GE, Blair E, De Klerk NH, Stanley FJ, Landau LI, et al. Breast feeding and cognitive development in childhood: a prospective birth cohort study. Paediatr Perinat Epidemiol. 2003;17:81-90.

73. Julvez J, Ribas-Fitó N, Forns M, Garcia-Esteban R, Torrent M, Sunyer J. Attention behaviour and hyperactivity at age 4 and duration of breastfeeding. Acta Paediatr. 2007;96:842-7.

74. Kadziela-Olech H, Piotrowska-Jastrzebska J. The duration of breastfeeding and attention deficit hyperactivity disorder. Rocz Akad Med Bialymst. 2005;50:302-6.

75. Mimouni-Bloch A, Kachevanskaya A, Mimouni FB, Shuper A, Raveh E, Linder N. Breastfeeding may protect from developing attention-deficit/ hyperactivity disorder. Breastfeed Med. 2013;8:363-7.

76. Shamberger R. Attention-deficit disorder associated with breast-feeding: a brief report. J Am Coll Nutr. 2012;31:239-42

77. Pu S, Nakagome K, Yamada T, Matsumura H, Yokoyama K, Kaneko K, et al. Association between fish consumption and prefrontal function during a cognitive task in male Japanese workers: A multi-channel near-infrared spectroscopy study. PLoS One. 2015;10:e0123972.

78. Jackson PA, Reay JL, Scholey AB, Kennedy DO. DHA-rich oil modulates the cerebral haemodynamic response to cognitive tasks in healthy young adults: a near IR spectroscopy pilot study. Br J Nutr. 2012;107:1093-8.

79. McNamara RK, Able JA, Jandacek RJ, Rider T, Tso P, Eliassen JC, et al. Docosahexaenoic acid supplementation increases prefrontal cortex activation during sustained attention in healthy boys: a placebo-controlled, dose-ranging, functional magnetic resonance imaging study. Am J Clin Nutr. 2010;91:1060-7.

80. Bauer I, Hughes M, Rowsell R, Cockerell R, Pipingas A, Crewther S, et al. Omega-3 supplementation improves cognition and modifies brain activation in young adults. Hum Psychopharmacol. 2014;29:133-44.

81. Almeida DM, Jandacek RJ, Weber WA, McNamara RK. Docosahexaenoic acid biostatus is associated with event-related functional connectivity in cortical attention networks of typically developing children. Nutr Neurosci. 2016, [Epub ahead of print] 
82. McNamara RK, Jandacek RJ, Rider T, Tso P, Weber W, Chu W-J, et al. Low docosahexaenoic acid status is associated with reduced indices of cortical integrity in the anterior cingulate of healthy male children: A ${ }^{1} \mathrm{H}$ MRS study. Nutr Neurosci. 2013;16:183-90.

83. Conklin SM, Gianaros PJ, Brown SM, Yao JK, Hariri AR, Manuck SB, et al. Longchain omega-3 fatty acid intake is associated positively with corticolimbic gray matter volume in healthy adults. Neurosci Lett. 2007;421:209-12.

84. Samieri C, Maillard P, Crivello F, Proust-Lima C, Peuchant E, Helmer C, et al. Plasma long-chain omega-3 fatty acids and atrophy of the medial temporal lobe. Neurology. 2012;79:642-50.

85. Titova OE, Sjögren P, Brooks SJ, Kullberg J, Ax E, Kilander L, et al. Dietary intake of eicosapentaenoic and docosahexaenoic acids is linked to gray matter volume and cognitive function in elderly. Age (Dordr). 2013;35:1495-505.

86. Pottala JV, Yaffe K, Robinson JG, Espeland MA, Wallace R, Harris WS. Higher RBC EPA + DHA corresponds with larger total brain and hippocampal volumes: WHIMS-MRI study. Neurology. 2014;82:435-42.

87. Hibbeln JR. Fish consumption and major depression. Lancet. 1998;351:1213.

88. Peet M. International variations in the outcome of schizophrenia and the prevalence of depression in relation to national dietary practices: an ecological analysis. Br J Psychiatry. 2004;184:404-8.

89. Hibbeln JR. Seafood consumption, the DHA content of mothers' milk and prevalence rates of postpartum depression: a cross-national, ecological analysis. J Affect Disord. 2002;69:15-29.

90. Noaghiul S, Hibbeln JR. Cross-national comparisons of seafood consumption and rates of bipolar disorders. Am J Psychiatry. 2003;160:2222-7.

91. Christensen O, Christensen E. Fat consumption and schizophrenia. Acta Psychiatr Scand. 1988;78:587-91.

92. Polanczyk G, de Lima MS, Horta BL, Biederman J, Rohde LA. The worldwide prevalence of ADHD: a systematic review and metaregression analysis. Am J Psychiatry. 2007;164:942-8.

93. Allen KL, Mori TA, Beilin L, Byrne SM, Hickling S, Oddy WH. Dietary intake in population-based adolescents: support for a relationship between eating disorder symptoms, low fatty acid intake and depressive symptoms. J Hum Nutr Diet. 2013;26:459-69.

94. Murakami K, Miyake Y, Sasaki S, Tanaka K, Arakawa M. Fish and n-3 polyunsaturated fatty acid intake and depressive symptoms: Ryukyus Child Health Study. Pediatrics. 2010;126:623-30.

95. Oddy WH, Hickling S, Smith MA, O'Sullivan TA, Robinson M, de Klerk NH, et al. Dietary intake of omega-3 fatty acids and risk of depressive symptoms in adolescents. Depress Anxiety. 2011;28:582-8.

96. Swenne I, Rosling A, Tengblad S, Vessby B. Omega-3 polyunsaturated essential fatty acids are associated with depression in adolescents with eating disorders and weight loss. Acta Paediatr. 2011;100:1610-5.

97. McGrath-Hanna NK, Greene DM, Tavernier RJ, Bult-Ito A. Diet and mental health in the Arctic: is diet an important risk factor for mental health in circumpolar peoples? A review. Int J Circumpolar Health. 2003;62:228-41.

98. Angst F, Stassen HH, Clayton PJ, Angst J. Mortality of patients with mood disorders: follow-up over 34-38 years. J Affect Disord. 2002;68:167-81.

99. Osby U, Brandt L, Correia N, Ekbom A, Sparén P. Excess mortality in bipolar and unipolar disorder in Sweden. Arch Gen Psychiatry. 2001;58:844-50.

100. Brown S. Excess mortality of schizophrenia. A meta-analysis. Br J Psychiatry. 1997;171:502-8.

101. Osby U, Correia N, Brandt L, Ekbom A, Sparén P. Mortality and causes of death in schizophrenia in Stockholm county, Sweden. Schizophr Res. 2000;45:21-8.

102. Tanskanen A, Hibbeln JR, Hintikka J, Haatainen K, Honkalampi K, Viinamäki H. Fish consumption, depression, and suicidality in a general population. Arch Gen Psychiatry. 2001;58:512-3

103. De Vriese SR, Christophe AB, Maes M. In humans, the seasonal variation in poly-unsaturated fatty acids is related to the seasonal variation in violent suicide and serotonergic markers of violent suicide. Prostaglandins Leukot Essent Fatty Acids. 2004;71:13-8.

104. Garland MR, Hallahan B, McNamara M, Carney PA, Grimes H, Hibbeln JR, et al. Lipids and essential fatty acids in patients presenting with self-harm. Br J Psychiatry. 2007;190:112-7.

105. Huan M, Hamazaki K, Sun Y, Itomura M, Liu H, Kang W, et al. Suicide attempt and $\mathrm{n}-3$ fatty acid levels in red blood cells: a case control study in China. Biol Psychiatry. 2004;56:490-6.

106. Sublette ME, Hibbeln JR, Galfalvy H, Oquendo MA, Mann JJ. Omega-3 polyunsaturated essential fatty acid status as a predictor of future suicide risk. Am J Psychiatry. 2006;163:1100-2.
107. Hallahan B, Hibbeln JR, Davis JM, Garland MR. Omega-3 fatty acid supplementation in patients with recurrent self-harm. Single-centre double-blind randomised controlled trial. Br J Psychiatry. 2007;190:118-22.

108. Peet M, Horrobin DF. A dose-ranging study of the effects of ethyleicosapentaenoate in patients with ongoing depression despite apparently adequate treatment with standard drugs. Arch Gen Psychiatry. 2002;59:913-9.

109. Tsai AC, Lucas M, Okereke OI, O'Reilly EJ, Mirzaei F, Kawachi I, et al. Suicide mortality in relation to dietary intake of n-3 and n-6 polyunsaturated fatty acids and fish: equivocal findings from 3 large US cohort studies. Am J Epidemiol. 2014;179:1458-66.

110. Goldstein BI, Carnethon MR, Matthews KA, Mclntyre RS, Miller GE, Raghuveer G, et al. Major depressive disorder and bipolar disorder predispose youth to accelerated atherosclerosis and early cardiovascular disease: a scientific statement from the American Heart Association. Circulation. 2015;132:965-86.

111. Harris WS. The omega-3 index as a risk factor for coronary heart disease. Am J Clin Nutr. 2008;87:1997S-2002S.

112. Whelton SP, He J, Whelton PK, Muntner P. Meta-analysis of observational studies on fish intake and coronary heart disease. Am J Cardiol. 2004;93:1119-23.

113. Baghai TC, Varallo-Bedarida G, Born C, Häfner S, Schüle C, Eser D, et al. Major depressive disorder is associated with cardiovascular risk factors and low Omega-3 Index. J Clin Psychiatry. 2011;72:1242-7.

114. Fontes JD, Rahman F, Lacey S, Larson MG, Vasan RS, Benjamin EJ, et al. Red blood cell fatty acids and biomarkers of inflammation: a cross-sectional study in a community-based cohort. Atherosclerosis. 2015;240:431-6.

115. McKenney JM, Sica D. Role of prescription omega-3 fatty acids in the treatment of hypertriglyceridemia. Pharmacotherapy. 2007;27:715-28.

116. Albert CM, Campos H, Stampfer MJ, Ridker PM, Manson JE, Willett WC, et al. Blood levels of long-chain $n-3$ fatty acids and the risk of sudden death. N Engl J Med. 2002;346:1113-8.

117. Siscovick DS, Raghunathan TE, King I, Weinmann S, Wicklund KG, Albright J, et al. Dietary intake and cell membrane levels of long-chain n-3 polyunsaturated fatty acids and the risk of primary cardiac arrest. JAMA. 1995;274:1363-7.

118. Harris WS, Von Schacky C. The Omega-3 Index: a new risk factor for death from coronary heart disease? Prev Med. 2004:39:212-20.

119. Block RC, Harris WS, Reid KJ, Sands SA, Spertus JA. EPA and DHA in blood cell membranes from acute coronary syndrome patients and controls. Atherosclerosis. 2008;197:821-8.

120. Kwak SM, Myung SK, Lee YJ, Seo HG. Korean Meta-analysis Study Group. Efficacy of omega-3 fatty acid supplements (eicosapentaenoic acid and docosahexaenoic acid) in the secondary prevention of cardiovascular disease: a meta-analysis of randomized, double-blind, placebo-controlled trials. Arch Intern Med. 2012;172:686-94.

121. Wang C, Harris WS, Chung M, Lichtenstein AH, Balk EM, Kupelnick B, et al. n-3 Fatty acids from fish or fish-oil supplements, but not alpha-linolenic acid, benefit cardiovascular disease outcomes in primary- and secondary-prevention studies: a systematic review. Am J Clin Nutr. 2006;84:5-17.

122. Einvik G, Klemsdal TO, Sandvik L, Hjerkinn EM. A randomized clinical trial on n-3 polyunsaturated fatty acids supplementation and all-cause mortality in elderly men at high cardiovascular risk. Eur J Cardiovasc Prev Rehabil. 2010;17:588-92.

123. Sands SA, Reid KJ, Windsor SL, Harris WS. The impact of age, body mass index, and fish intake on the EPA and DHA content of human erythrocytes. Lipids. 2005:40:343-7.

124. Itomura M, Fujioka S, Hamazaki K, Kobayashi K, Nagasawa T, Sawazaki S, et al. Factors influencing EPA + DHA levels in red blood cells in Japan. In Vivo. 2008;22:131-5

125. Flock MR, Skulas-Ray AC, Harris WS, Etherton TD, Fleming JA, Kris-Etherton PM. Determinants of erythrocyte omega-3 fatty acid content in response to fish oil supplementation: a dose-response randomized controlled trial. J Am Heart Assoc. 2013;2, e000513.

126. Lin PY, Huang SY, Su KP. A meta-analytic review of polyunsaturated fatty acid compositions in patients with depression. Biol Psychiatry. 2010;68:140-7.

127. Chiu CC, Huang SY, Su KP, Lu ML, Huang MC, Chen CC, et al. Polyunsaturated fatty acid deficit in patients with bipolar mania. Eur Neuropsychopharmacol. 2003;13:99-103.

128. McNamara RK, Jandacek R, Rider T, Tso P, Dwivedi Y, Pandey GN. Selective deficits in erythrocyte docosahexaenoic acid composition in adult patients with bipolar disorder and major depressive disorder. J Affect Disord. 2010;126:303-11. 
129. Ranjekar PK, Hinge A, Hegde MV, Ghate M, Kale A, Sitasawad S, et al. Decreased antioxidant enzymes and membrane essential polyunsaturated fatty acids in schizophrenic and bipolar mood disorder patients. Psychiatry Res. 2003;121:109-22.

130. McNamara RK, Jandacek RJ, Tso P, Blom TJ, Welge JA, Strawn JR, et al. First-episode bipolar disorder is associated with erythrocyte membrane docosahexaenoic acid deficits: Dissociation from clinical response to lithium or quetiapine. Psychiatry Res. 2015;230:447-53.

131. Clayton EH, Hanstock TL, Hirneth SJ, Kable CJ, Garg ML, Hazell PL. Long-chain omega-3 polyunsaturated fatty acids in the blood of children and adolescents with juvenile bipolar disorder. Lipids. 2008;43:1031-8.

132. Pottala JV, Talley JA, Churchill SW, Lynch DA, von Schacky C, Harris WS. Red blood cell fatty acids are associated with depression in a case-control study of adolescents. Prostaglandins Leukot Essent Fatty Acids. 2012;86:161-5.

133. McNamara RK, Jandacek RJ, Tso P, Blom TJ, Welge JA, Strawn JR, et al. Adolescents with or at ultra-high risk for bipolar disorder exhibit erythrocyte docosahexaenoic and eicosapentaenoic acid deficits: A candidate prodromal risk biomarker. Early Interv Psychiatry. 2016, [Epub ahead of print].

134. McNamara RK, Strimpfel J, Jandacek RJ, Rider T, Tso P, Welge J, et al. Detection and treatment of long-chain omega-3 fatty acid deficiency in adolescents with SSRI-resistant major depressive disorder. PharmaNutrition. 2014;2:38-46.

135. Green P, Hermesh H, Monselise A, Marom S, Presburger G, Weizman A. Red cell membrane omega-3 fatty acids are decreased in nondepressed patients with social anxiety disorder. Eur Neuropsychopharmacol. 2006;16:107-13.

136. Liu JJ, Galfalvy HC, Cooper TB, Oquendo MA, Grunebaum MF, Mann JJ, et al. Omega-3 polyunsaturated fatty acid (PUFA) status in major depressive disorder with comorbid anxiety disorders. J Clin Psychiatry. 2013;74:732-8.

137. Khan MM, Evans DR, Gunna V, Scheffer RE, Parikh W, Mahadik SP. Reduced erythrocyte membrane essential fatty acids and increased lipid peroxides in schizophrenia at the never-medicated first-episode of psychosis and after years of treatment with antipsychotics. Schizophr Res. 2002:58:1-10.

138. Reddy RD, Keshavan MS, Yao JK. Reduced red blood cell membrane essential polyunsaturated fatty acids in first episode schizophrenia at neuroleptic-naive baseline. Schizophr Bull. 2004;30:901-11.

139. Evans DR, Parikh W, Khan MM, Coussons C, Buckley PF, Mahadik SP. Red blood cell membrane essential fatty acid metabolism in early psychotic patients following antipsychotic drug treatment. Prostaglandins Leukot Essent Fatty Acids. 2003;69:393-9.

140. Hoen WP, Lijmer JG, Duran M, Wanders RJ, van Beveren NJ, de Haan L. Red blood cell polyunsaturated fatty acids measured in red blood cells and schizophrenia: a meta-analysis. Psychiatry Res. 2013;207:1-12.

141. Hawkey E, Nigg JT. Omega-3 fatty acid and ADHD: Blood level analysis and meta-analytic extension of supplementation trials. Clin Psychol Rev. 2014;34:496-505.

142. Carver JD, Benford VJ, Han B, Cantor AB. The relationship between age and the fatty acid composition of cerebral cortex and erythrocytes in human subjects. Brain Res Bull. 2001;56:79-85.

143. McNamara RK, Hahn C-G, Jandacek R, Rider T, Tso P, Stanford K, et al. Selective deficits in the omega-3 fatty acid docosahexaenoic acid in the postmortem orbitofrontal cortex of patients with major depressive disorder. Biol Psychiatry. 2007;62:17-24.

144. McNamara RK, Jandacek R, Rider T, Tso P, Richtand NM, Stanford K. Abnormalities in the fatty acid composition of the postmortem orbitofrontal cortex of schizophrenic patients: Gender differences and partial normalization with antipsychotic medications. Schizophr Res. 2007:91:37-50.

145. McNamara RK, Jandacek R, Rider T, Tso P, Stanford K, Hahn C-G, et al. Deficits in docosahexaenoic acid and associated elevations in the metabolism of arachidonic acid and saturated fatty acids in the postmortem orbitofrontal cortex of patients with bipolar disorder. Psychiatric Res. 2008;160:285-99.

146. Tatebayashi $Y$, Nihonmatsu-Kikuchi N, Hayashi $Y, Y u$ X, Soma M, Ikeda K. Abnormal fatty acid composition in the frontopolar cortex of patients with affective disorders. Transl Psychiatry. 2013;2:e204.

147. Conklin SM, Runyan CA, Leonard S, Reddy RD, Muldoon MF, Yao JK. Age-related changes of $n-3$ and $n-6$ polyunsaturated fatty acids in the anterior cingulate cortex of individuals with major depressive disorder. Prostaglandins Leukot Essent Fatty Acids. 2010;82:111-9.
148. Igarashi M, Ma K, Gao F, Kim HW, Greenstein D, Rapoport SI, et al. Brain lipid concentrations in bipolar disorder. J Psychiatr Res. 2010;44:177-82.

149. Lalovic A, Levy E, Canetti L, Sequeira A, Montoudis A, Turecki G. Fatty acid composition in postmortem brains of people who completed suicide. J Psychiatry Neurosci. 2007;32:363-70.

150. Yao JK, Leonard S, Reddy RD. Membrane phospholipid abnormalities in postmortem brains from schizophrenic patients. Schizophr Res. 2000;42:7-17.

151. McNamara RK, Jandacek RJ. Investigation of postmortem brain polyunsaturated fatty acid composition in psychiatric disorders: Limitations, challenges, and future directions. J Psychiatr Res. 2011;45:44-6.

152. Kempton MJ, Salvador Z, Munafò MR, Geddes JR, Simmons A, Frangou S, et al. Structural neuroimaging studies in major depressive disorder. Meta-analysis and comparison with bipolar disorder. Arch Gen Psychiatry. 2011;68:675-90.

153. Castellanos FX, Lee PP, Sharp W, Jeffries NO, Greenstein DK, Clasen LS, et al. Developmental trajectories of brain volume abnormalities in children and adolescents with attention-deficit/hyperactivity disorder. JAMA. 2002;288:1740-8.

154. Glahn DC, Laird AR, Ellison-Wright I, Thelen SM, Robinson JL, Lancaster $J$, et al. Meta-analysis of gray matter anomalies in schizophrenia: application of anatomic likelihood estimation and network analysis. Biol Psychiatry. 2008;64:774-81.

155. Chhetry BT, Hezghia A, Miller JM, Lee S, Rubin-Falcone H, Cooper TB, et al. Omega-3 polyunsaturated fatty acid supplementation and white matter changes in major depression. J Psychiatr Res. 2016;75:65-74.

156. Amminger GP, Schäfer MR, Papageorgiou K, Klier CM, Cotton SM, Harrigan SM, et al. Long-chain omega-3 fatty acids for indicated prevention of psychotic disorders: a randomized, placebo-controlled trial. Arch Gen Psychiatry. 2010;67:146-54.

157. Wozniak J, Biederman J, Mick E, Waxmonsky J, Hantsoo L, Best C, et al. Omega-3 fatty acid monotherapy for pediatric bipolar disorder: a prospective open-label trial. Eur Neuropsychopharmacol. 2007;17:440-7.

158. Clayton EH, Hanstock TL, Hirneth SJ, Kable CJ, Garg ML, Hazell PL. Reduced mania and depression in juvenile bipolar disorder associated with long-chain omega-3 polyunsaturated fatty acid supplementation. Eur J Clin Nutr. 2009;63:1037-40.

159. Bloch MH, Qawasmi A. Omega-3 fatty acid supplementation for the treatment of children with attention-deficit/hyperactivity disorder symptomatology: systematic review and meta-analysis. J Am Acad Child Adolesc Psychiatry. 2011;50:991-1000.

160. Emsley R, Myburgh C, Oosthuizen P, van Rensburg SJ. Randomized, placebo-controlled study of ethyl-eicosapentaenoic acid as supplemental treatment in schizophrenia. Am J Psychiatry. 2002;159:1596-8.

161. Mellor JE, Laugharne JD, Peet M. Schizophrenic symptoms and dietary intake of n-3 fatty acids. Schizoph Res. 1995;18:85-6.

162. Chen AT, Chibnall JT, Nasrallah HA. A meta-analysis of placebocontrolled trials of omega-3 fatty acid augmentation in schizophrenia: Possible stage-specific effects. Ann Clin Psychiatry. 2015;27:289-96.

163. Nemets $H$, Nemets B, Apter A, Bracha Z, Belmaker RH. Omega-3 treatment of childhood depression: a controlled, double-blind pilot study. Am J Psychiatry. 2006;163:1098-100.

164. Grosso G, Pajak A, Marventano S, Castellano S, Galvano F, Bucolo C, et al. Role of omega-3 fatty acids in the treatment of depressive disorders: a comprehensive meta-analysis of randomized clinical trials. PLoS One. 2014;9:e96905.

165. Sublette ME, Ellis SP, Geant AL, Mann JJ. Meta-analysis of the effects of eicosapentaenoic acid (EPA) in clinical trials in depression. J Clin Psychiatry. 2011;72:1577-84.

166. Sarris J, Mischoulon D, Schweitzer I. Omega-3 for bipolar disorder: meta-analyses of use in mania and bipolar depression. J Clin Psychiatry. 2012;73:81-6.

167. Appleton KM, Sallis HM, Perry R, Ness AR, Churchill R. Omega-3 fatty acids for depression in adults. Cochrane Database Syst Rev. 2015;11:CD004692.

168. Jazayeri S, Tehrani-Doost M, Keshavarz SA, Hosseini M, Djazayery A, Amini H, et al. Comparison of therapeutic effects of omega-3 fatty acid eicosapentaenoic acid and fluoxetine, separately and in combination, in major depressive disorder. Aust N Z J Psychiatry. 2008;42:192-8.

169. Gertsik L, Poland RE, Bresee C, Rapaport MH. Omega-3 fatty acid augmentation of citalopram treatment for patients with major depressive disorder. J Clin Psychopharmacol. 2012;32:61-4.

170. Stoll AL, Severus WE, Freeman MP, Rueter S, Zboyan HA, Diamond E, et al. Omega 3 fatty acids in bipolar disorder: a preliminary double-blind, placebo-controlled trial. Arch Gen Psychiatry. 1999;56:407-12.

171. Berger GE, Proffitt TM, McConchie M, Yuen H, Wood SJ, Amminger GP, et al. Ethyl-eicosapentaenoic acid in first-episode psychosis: a randomized, placebo-controlled trial. J Clin Psychiatry. 2007;68:1867-75. 
172. Peet M, Horrobin DF, E-E Multicentre Study Group. A dose-ranging exploratory study of the effects of ethyl-eicosapentaenoate in patients with persistent schizophrenic symptoms. J Psychiatr Res. 2002;36:7-18.

173. Caniato RN, Alvarenga ME, Garcia-Alcaraz MA. Effect of omega-3 fatty acids on the lipid profile of patients taking clozapine. Aust N Z J Psychiatry. 2006:40:691-7.

174. Freeman MP, Mclnerney K, Sosinsky AZ, Kwiatkowski MA, Cohen LS. Omega-3 fatty acids for atypical antipsychotic-associated hypertriglyceridemia. Ann Clin Psychiatry. 2015;27:197-202.

175. Gracious BL, Bhatt R, Potter C. Nonalcoholic fatty liver disease and fibrosis in youth taking psychotropic medications: Literature review, case reports, and management. J Child Adolesc Psychopharmacol. 2015;25:602-10.

176. Parker HM, Johnson NA, Burdon CA, Cohn JS, O'Connor HT, George J. Omega-3 supplementation and non-alcoholic fatty liver disease: a systematic review and meta-analysis. J Hepatol. 2012;56:944-51.

177. McNamara RK, Magrisso IJ, Hofacer RD, Jandacek RJ, Rider T, Tso P, et al. Omega-3 fatty acid deficiency augments risperidone-induced hepatic steatosis in rats: Positive association with stearoyl-CoA desaturase. Pharmacol Res. 2012;66:283-91.

178. McNamara RK, Jandacek RJ, Rider T, Tso P, Dwivedi Y, Pandey GN. Adult medication-free schizophrenic patients exhibit long-chain omega-3 fatty acid deficiency: Implications for cardiovascular disease risk. Cardiovasc Psychiatry Neurol. 2013;13:4-14

179. Freeman MP, Hibbeln JR, Wisner KL, Davis JM, Mischoulon D, Peet M, et al. Omega-3 fatty acids: evidence basis for treatment and future research in psychiatry. J Clin Psychiatry. 2006;67:1954-67.

180. Buckley MS, Goff AD, Knapp WE. Fish oil interaction with warfarin. Ann Pharmacother. 2004;38:50-2.

181. Eritsland J, Arnesen H, Seljeflot I, Kierulf P. Long-term effects of $n-3$ polyunsaturated fatty acids on haemostatic variables and bleeding episodes in patients with coronary artery disease. Blood Coagul Fibrinolysis. 1995;6:17-22.

182. Mueller BA, Talbert RL, Tegeler CH, Prihoda TJ. The bleeding time effects of a single dose of aspirin in subjects receiving omega-3 fatty acid dietary supplementation. J Clin Pharmacol. 1991;31:185-90

183. Harris WS. Expert opinion: omega-3 fatty acids and bleeding-cause for concern? Am J Cardiol. 2007;99:44C-6C.

184. DeGiorgio CM, Miller PR, Harper R, Gornbein J, Schrader L, Soss J, et al. Fish oil ( $n-3$ fatty acids) in drug resistant epilepsy: a randomised placebocontrolled crossover study. J Neurol Neurosurg Psychiatry. 2015;86:65-70.

185. Reda DM, Abd-El-Fatah NK, Omar T-S, Darwish OA. Fish oil intake and seizure control in children with medically resistant epilepsy. N Am J Med Sci. 2015;7:317-21.

\section{Submit your next manuscript to BioMed Central and we will help you at every step:}

- We accept pre-submission inquiries

- Our selector tool helps you to find the most relevant journal

- We provide round the clock customer support

- Convenient online submission

- Thorough peer review

- Inclusion in PubMed and all major indexing services

- Maximum visibility for your research

Submit your manuscript at www.biomedcentral.com/submit 